\title{
Factores que contribuyen a la participación de adolescentes en delitos violentos en México*
}

Elena Azaola Garrido

\section{Planteamiento del problema}

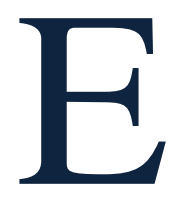
ste texto, que constituye la síntesis de un estudio más amplio, pretende ofrecer a los policías federales algunos elementos que podrían ser de utilidad para tener una comprensión más amplia acerca del fenómeno de la delincuencia juvenil en nuestro país, particularmente en los casos de los y las adolescentes que cometen delitos graves haciendo uso de la violencia.

El estudio que realizamos se propuso centrar su mirada sobre las condiciones de vulnerabilidad que enfrenta una porción significativa de la población adolescente en nuestro país, eligiendo para ello al sector de

los adolescentes que posiblemente manifiesta de la manera más extrema y dolorosa los efectos de dichas condiciones de vulnerabilidad. Nos referimos a la población de adolescentes que se encuentran privados de su libertad por haber cometido delitos graves. Intentamos con ello mostrar lo que etas condiciones son susceptibles de producir cuando no existen o no operan de manera adecuada, los mecanismos que deberían haber protegido a estos adolescentes e impedido que llegaran a los extremos que lo han hecho, 
produciendo graves daños tanto a la sociedad como a ellos mismos.

De manera específica, nos enfocamos en el subgrupo de edad de las y los adolescentes que pueden ser sujetos a la privación de libertad cuando han cometido delitos graves, es decir, a los adolescentes de entre 14 y 18 años de edad. En números redondos, México cuenta con casi 11 millones de adolescentes de 14 a 18 años, que representan cerca del $10 \%$ de la población total del país.

Recientemente, Save the Children publicó un valioso Informe al que tituló Las y los adolescentes que México ha olvidado. En dicho Informe señala que es frecuente que la adolescencia se incluya dentro de grupos de población más amplios, como el de las niñas y niños (0-17 años) o el de los jóvenes (15-29 años), borrando con ello los rasgos y las necesidades específica de los y las adolescentes (12-18 años). Este es uno de los rasgos que caracterizan a las y los adolescentes como una población excluida, señala el Informe, lo que resulta en la carencia de datos desagregados para esta población que permitan tener mayor claridad de los problemas que enfrenta y de la integralidad que requiere su atención. Esto, a su vez, impide diseñar políticas públicas enfocadas a los adolescentes, que cumplan con los criterios básicos de pertinencia, claridad y sustento del problema o problemas que se proponen resolver (Save the Children 2016).

Nuestro estudio no se propuso subsanar estas carencias, pero sí intenta hacer visible y, en la medida de lo posible, inteligible, la realidad que viven las y los adolescentes que se encuentran privados de su libertad por haber cometido delitos graves, particularmente en aquellos casos en que han hecho uso de la violencia. Hemos seleccionado a este subgrupo, no porque pensemos que pueden representar a los y las adolescentes en su conjunto y ni siquiera a todos los adolescentes que han infringido las leyes, sino precisamente porque consideramos que se trata de aquellos que están colocados en el extremo menos visible y más estigmatizado de entre los que, ya de por sí, se encuentran excluidos. De igual modo, hemos elegido particularmente a aquellos que han hecho uso de la violencia porque consideramos que éste es uno de los problemas más graves que enfrenta hoy en día nuestro país. Siendo así, aportar elementos que contribuyan a entender en profundidad el fenómeno de la violencia, constituye un paso imprescindible para poder reducir tanto su incidencia como los severos daños, muchas veces irreparables, que ocasiona, y que provoca consecuencias que pueden afectar a varias generaciones. 
Otro de los objetivos centrales del estudio, fue poder escuchar las voces y los testimonios de las y los adolescentes que se encuentran privados de libertad y que, por lo mismo, no tienen la oportunidad de ser escuchados. El estudio está construido, de hecho, a partir de sus historias, de los numerosos testimonios que hemos podido recabar y que reproducimos de manera textual.

El estudio se enmarca en los hallazgos científicos más recientes acerca del proceso de desarrollo en la adolescencia, que luego fueron reforzados por la investigación neuro científica. La adolescencia es ahora entendida como el periodo durante el cual el cerebro, no sólo se halla en proceso de maduración, sino que es extraordinariamente maleable $y$ vulnerable. Estos avances en las ciencias del comportamiento y la neurociencia constituyen el soporte conceptual que ha apuntalado las reformas a los sistemas de justicia juvenil que han tenido lugar durante la última década en distintos países (Cauffman and Steimberg 2000; Steimberg et al. 2006; Monahan et al. 2009; Mulvey 2011; Bonnie et al. 2013). Estas reformas han sido también impulsadas por el reconocimiento creciente de los efectos psicológicos y sociales negativos que han tenido las políticas punitivas y de mano dura, tanto para los adolescentes involucrados como para sus comunidades. Hoy se tiene claro que, la gran mayoría de los y las adolescentes, desiste de las conductas delictivas como resultado de su proceso natural de maduración, y que los programas que les brindan atención y servicios mientras permanecen en su comunidad, rinden mejores resultados que aquellos que los privan de la libertad, especialmente si esto ocurre por un periodo prolongado (MacArthur 2015).

Cabe aquí referirnos también a un Reporte que rindió el Procurador General de Estados Unidos, quien ordenó la conformación de un grupo especial de trabajo para que indagara los efectos que tiene la violencia en los niños $\mathrm{y}$ adolescentes que han sido expuestos a ella. En dicho Reporte se incluyó un capítulo que hace referencia a la necesidad de repensar el sistema de justicia juvenil en aquél país. En este capítulo se dice: "la gran mayoría de los niños involucrados en el sistema de justicia han sobrevivido expuestos a la violencia y viven con el trauma de dicha experiencia”. Señala también que la mayoría de estos niños han sido expuestos a diversos tipos de violencia durante el curso de sus vidas y la relación entre haber sido expuestos a la violencia y estar en manos de la justicia, no es una coincidencia. La exposición a la violencia, dice el Reporte, a menudo conduce a la desconfianza, la 
hipervigilancia, el comportamiento impulsivo, el aislamiento, las adicciones, la falta de empatía o la dificultad para poderse preocupar por los otros y la agresión como una manera de auto protegerse. Cuando los niños y adolescentes experimentan violencia de manera repetida o por periodos prolongados, su cuerpo y su cerebro se adaptan para enfocarse en su sobrevivencia. Esto reduce dramáticamente su habilidad para controlar sus impulsos y demorar la gratificación. Los adolescentes que están tratando de protegerse a sí mismos de la violencia, o que no saben cómo lidiar con las experiencias de violencia que han vivido, pueden engancharse en comportamientos delictivos como una manera de obtener una sensación de control sobre sus caóticas vidas y de lidiar con la confusión emocional y las barreras que genera la violencia para poder alcanzar la seguridad y el éxito (Department of Justice 2012: 171-172).

Muchos adolescentes en los sistemas de justicia, continúa el Reporte, parecen enojados, desafiantes o indiferentes, pero, en realidad, se encuentran temerosos, deprimidos $\mathrm{y}$ solitarios. Se hallan lastimados emocionalmente y se sienten impotentes, abandonados y sujetos a dobles estándares tanto por parte de los adultos con quienes han vivido, como de las instituciones. A menudo, el sistema ve a estos niños como carentes de un futuro esperanzador e incontrolables, por lo que suelen etiquetarlos como 'oposicionistas', 'deliberadamente irresponsables' $y$, en último término, como 'intratables'. Lo que parece como un desafío intencional y una actitud agresiva, es a menudo una defensa en contra de la desesperación y la falta de expectativas que la violencia ha provocado en la vida de estos adolescentes.

Por último, el Reporte advierte que, cuando el sistema de justicia juvenil responde sólo con castigos, estos adolescentes pueden ser impulsados a formar parte del sistema de justicia penal para adultos, resultando entonces en una pérdida permanente para sus familias y para la sociedad. "Al fracasar en identificar y tratar adecuadamente a los niños y adolescentes que han sido expuestos a la violencia, el sistema pierde la oportunidad para modificar su comportamiento delictivo" (2012: 173).

Por nuestra parte, no sostenemos que existe un factor único que pueda explicar los comportamientos delictivos de los adolescentes, sino que invariablemente se trata de un conjunto de factores, cuyo peso específico varía, y que interactúan siguiendo ciertos patrones o trayectorias que es posible trazar y que conducen a ese 
resultado. No obstante, en el imaginario social, pero también incluso entre el personal de las instituciones que atienden a los adolescentes, suelen prevalecer creencias que tienden a simplificar los factores que pueden dar origen al comportamiento delictivo juvenil. Por ejemplo, la pobreza suele citarse como una de las causas, siendo que $53 \%$ de la población de adolescentes se encuentra en esta situación y ni siquiera el $1 \%$ se encuentra detenido por haber cometido algún delito. Lo mismo ocurre con el tema de la separación de los padres, ya que sabemos que en nuestro país $29 \%$ de los hogares se hallan encabezados por mujeres. En ambos casos se trata de circunstancias que, con frecuencia, afectan a las familias pero que dependerá de sus capacidades, de la resilencia, la calidad de los vínculos que existan entre sus integrantes y de sus lazos con la comunidad, entre otros factores, la manera en que podrán hacer frente, o no, a dichas circunstancias. Es decir, la pobreza y la separación de los padres, si bien pueden tener alguna incidencia, requieren del concurso de otros factores como, por ejemplo, el bajo nivel de escolaridad de los padres, sus dificultades para supervisar, guiar y contener a los hijos y para trazar normas y ejercer límites, la deserción escolar de los hijos, el abandono, el rechazo, la negligencia, la violencia, el abuso sexual, el consumo de sustancias y/o el contacto con grupos delictivos, para que, combinados, tengan un impacto en la conducta de los adolescentes. Cabe señalar que estos factores pueden asociarse a la pobreza, pero también pueden tener lugar en cualquier otro estrato social.

Lo anterior no significa que la pobreza no coloque en situaciones de grave desventaja a quienes la padecen y que, a menudo, se asocie con otros factores de vulnerabilidad que, sumados, puedan tener un impacto en los comportamientos que se apartan de las normas.

\section{Metodología}

Para recolectar la información, empleamos un conjunto de métodos y técnicas de investigación tanto de corte cuantitativo como cualitativo. Entre ellos, levantamos una encuesta y recogimos los testimonios directos de 730 adolescentes que se encuentran privados de su libertad en centros de internamiento de 17 entidades representativas de todas las regiones del país. Esta población representa casi la quinta parte (19\%) de la población total de los y las adolescentes privados de libertad, por lo que el estudio que realizamos nos ofrece un panorama bastante completo $\mathrm{y}$ detallado de la problemática que enfrenta este subgrupo de adolescentes vulnerables en nuestro país. 
La población objetivo es la población total de las y los adolescentes en conflicto con la ley que, por haber cometido delitos graves, se encuentran privados de su libertad en el país. A inicios de 2016, esta población era de 3,761 adolescentes de los que 3,600 eran hombres (96\%) y 161 mujeres $(4 \%)^{1}$.

Cabe señalar que en el país también existía en ese momento un total de 13,327 adolescentes sujetos a diversas medidas por haber cometido delitos, por lo que los 3,761 que se encontraban privados de su libertad, representaban $28 \%$ de los adolescentes; es decir, que el $72 \%$ restante había cometido delitos no graves, que no ameritaron la privación de la libertad y, por tanto, no son sujetos de este estudio.

Con el propósito de tener un panorama lo más completo posible, seleccionamos 17 entidades de la República, que representan a todas las regiones del país, a las que acudimos para entrevistar a las y los adolescentes que se encuentran privados de su libertad ${ }^{2}$. Las 17 entidades que elegimos como representativas, son:

\footnotetext{
1 Datos proporcionados, en enero de 2016, por el Órgano Administrativo Desconcentrado de Prevención y Readaptación Social.

2 De los diecisiete estados comprendidos en la muestra, cuatro: Hidalgo, Morelos, Sinaloa y
}

Región Norte: Chihuahua, Durango, Sonora, Coahuila, Sinaloa, Baja California y Zacatecas.

Región Centro: Puebla, Morelos, Hidalgo, Ciudad de México, Estado de México y Jalisco.

Región Sur: Oaxaca, Yucatán, Tabasco y Veracruz.

En relación con la cobertura, el estudio más amplio proporciona información precisa y confiable de las características socio demográficas y económicas de las y los adolescentes que han cometido delitos graves, especialmente de tipo violento; de los factores de vulnerabilidad que en su historia y su entorno contribuyeron a que su conducta se apartara de las normas; de los tipos de delitos en que participaron; de los patrones de ingreso y permanencia en grupos delictivos y del cumplimiento de las normas del debido proceso a partir del momento en que fueron detenidos hasta la situación en que se encuentran en los centros de internamiento y de los programas que se les ofrecen para su reinserción.

Coahuila fueron visitados en 2014, pero agregamos los resultados que obtuvimos en aquel primer diagnóstico ya que fue realizado con la misma metodología e instrumentos que se utilizaron en las trece entidades restantes que visitamos en 2016. 
En el presente capítulo, por razones de espacio, sólo nos será posible ocuparnos de los tipos de delitos violentos que cometen los adolescentes.

En el estudio más amplio, la combinación de las herramientas de tipo cuantitativo y cualitativo nos brindó la posibilidad de obtener dos tipos de conocimiento que son muy valiosos y que resultan complementarios. La encuesta nos permitió, por un lado, formarnos una idea muy clara acerca de las características del conjunto de la población que se halla en los centros de internamiento para adolescentes de las entidades que estudiamos. Las historias que reconstruimos nos permitieron, en cambio, tener una perspectiva más profunda de los rasgos específicos y de las trayectorias de vida individuales. En este sentido, tenemos claro que el estudio completo contiene una riqueza de datos e información que aquí no nos ha sido posible incluir y que, aún en el estudio más amplio, nuestro análisis e interpretación está muy lejos de haber podido agotar.

\section{Los delitos violentos}

Formulamos a los adolescentes varias preguntas en relación con el delito o los delitos por los que se encuentran privados de su libertad. En primer término, les preguntamos si, en la colonia donde vivían, tenían amigos y si consideran que esos amigos tuvieron alguna influencia en que ellos o ellas se hubieran involucrado en actividades delictivas. Dos terceras partes (67\%) de las y los adolescentes respondieron que sí consideran que los amigos con quienes se relacionaban en su colonia, influyeron en que se involucraran en actividades delictivas.

El cuadro siguiente muestra el promedio de los porcentajes de la población de adolescentes por delito, de acuerdo con las estadísticas que nos proporcionaron las autoridades de las trece entidades a las que acudimos a entrevistar a los adolescentes en $2016^{3}$.

\section{Porcentaje de adolescentes privados de libertad por delito, 2016}

que, en las cuatro entidades estudiadas en 2014, no nos fue posible obtener este dato.

\footnotetext{
${ }^{3}$ En este caso, los datos se refieren sólo al promedio de la población de adolescentes internos por delito en las trece entidades a las que acudimos en 2016, ya
} 


\begin{tabular}{|l|c|}
\hline \multicolumn{1}{|c|}{ Delito } & \% \\
\hline Homicidio & 34 \\
\hline Robo con violencia & 24 \\
\hline Secuestro & 13 \\
\hline Violación & 12 \\
\hline Robo de vehículo & 4 \\
\hline Delitos contra la salud & 3 \\
\hline Robo simple & 3 \\
\hline Portación arma prohibida & 2 \\
\hline Pederastia & 1 \\
\hline Lesiones & 1 \\
\hline Otros & 3 \\
\hline TOTAL & $\mathbf{1 0 0}$ \\
\hline
\end{tabular}

Como se puede observar, los cuatro primeros delitos: homicidio, robo con violencia, secuestro y violación, representan $83 \%$ del total de los delitos por los que se encuentran privados de su libertad las y los adolescentes en las entidades que estudiamos. Este dato resulta consistente con lo que establece la Ley en el sentido de que sólo debe privarse de la libertad a los adolescentes que hubieran cometido delitos graves. Asimismo, vale la pena destacar que la decisión de centrar nuestro estudio en los y las adolescentes que hubieran hecho uso de la violencia, comprende a, por lo menos, $83 \%$ del total de la población de adolescentes privados de su libertad.

Por otro lado, también se les preguntó a los adolescentes si, antes de cometer el delito por el que se encuentran privados de su libertad, ya habían sido detenidos con anterioridad. Al respecto:
- 35\% dijo que sí habían sido detenidos previamente (de los que, 33\% habían sido detenidos una vez; $23 \%$ dos veces y $44 \%$ tres o más veces).

Este dato muestra que, por lo menos una tercera parte de los y las adolescentes, no eran primo- delincuentes, sino que llevaban algún tiempo cometiendo delitos. Ello nos permite hacer ver que, el hecho de que continuaran delinquiendo $\mathrm{y}$, sobre todo, escalando en los niveles de violencia, no sólo es responsabilidad de quienes cometieron esos actos sino también de quienes, en su entorno, no fueron capaces de contenerlos y brindarles oportunamente la atención que requerían, lo que quizás pudo haber evitado importantes daños para ellos mismos y para la sociedad.

\section{Modalidades de la actividad delictiva}


Los relatos que los adolescentes hicieron acerca del delito que cometieron, nos permiten distinguir claramente tres grupos que apuntan a características o modalidades distintas de la conducta delictiva.

1.En un primer grupo, están los adolescentes que señalaron haber cometido el delito siendo parte de un grupo de delincuencia organizada que, generalmente, se ocupaba de traficar drogas y/o armas, de organizar secuestros y de enfrentar violentamente a grupos rivales. En ocasiones, los adolescentes proporcionaron el nombre de ese grupo, las razones o la manera como ingresaron $y$ las funciones que desempeñaban.

2. En un segundo grupo estarán los adolescentes que dijeron haber cometido el delito porque formaban parte de alguna pandilla o banda en su colonia la que, generalmente, se reunía con el propósito de organizar fiestas, beber $\mathrm{y} / \mathrm{o}$ consumir drogas $\mathrm{y}$, a veces, pero no siempre, para robar o enfrentarse con otras pandillas que invadían o disputaban su territorio.

3.Por último, en un tercer grupo se encuentran los adolescentes que dijeron haber cometido el delito solos, o con algún amigo, pero sin que formaran parte de algún grupo o banda delictiva. En este último caso se encuentran adolescentes que pudieron haber cometido homicidios por conflictos personales o familiares, o en el contexto de algún robo $\mathrm{o}$ violación.

A continuación, haremos un análisis detallado de cada una de estas tres modalidades delictivas que nos parece importante distinguir ya que, en la medida que tengamos claras las características diferentes de estas conductas, que obedecen a circunstancias y motivaciones distintas, será posible diseñar las políticas que se requieren en cada caso para prevenir que más adolescentes incurran en las mismas. De este modo, analizaremos primero los rasgos distintivos de los delitos que cometen las y los adolescentes que formaban parte de grupos de la delincuencia 
organizada; en segundo término, los de los delitos que se cometen en pandilla y, por último, los que se cometen de manera individual.

\section{Crimen organizado}

Del total de 452 entrevistas que realizamos en trece estados, encontramos un total de 160 adolescentes (35\%) que señalaron que formaban parte de un grupo de la delincuencia organizada.

Entre los rasgos que caracterizan los delitos y las motivaciones de las y los adolescentes entrevistados que formaban parte de grupos de la delincuencia organizada, se hallan los siguientes, sin pretender hacer un recuento exhaustivo:

- Existe el deseo de imitar un estilo de vida que los adolescentes han podido observar en su entorno y que incluye: armas, autos, alcohol, drogas, sensación de poder y otros lujos y excesos a los que consideran que sólo pueden acceder uniéndose a esos grupos

- También existen modelos o personajes dentro de esos grupos que ellos desean imitar

- Tienen el deseo de formar parte de un grupo que les brinde la sensación de pertenencia, de protección, de solidaridad, equivalentes o sustitutas a las de una familia

- Algunos han normalizado la pertenencia a esos grupos como resultado de haber crecido $\mathrm{y}$ convivido de manera cotidiana con una familia que formaba parte de los mismos

- Se les hace creer que las personas a las que dañan lo merecían porque habían obtenido dinero, bienes o un status social de manera indebida, o bien por ser enemigos o disputar el territorio de su grupo

- También se les hace creer que ellos deben estar dispuestos a acatar y ejecutar todas las órdenes que se les den, lo que, ante ellos mismos, podría darles la sensación de no tener responsabilidad ya que sólo obedecían órdenes

- La adrenalina que les produce vivir constantemente en situaciones de peligro, resulta atractiva para algunos jóvenes

- Formar parte del grupo les produce una sensación de dominio, de control, de formar parte de un poder paralelo que disputa o pretende substituir al poder del Estado

- La participación en algunos grupos de 
ex militares o policías, contribuye a que la línea que divide lo legal de lo ilegal, se difumine, y contribuye a que los adolescentes adopten una actitud cínica frente a sus propios actos ilegales

- Formar parte de estos grupos, en un entorno donde gozan de aceptación, les brinda status y, en este sentido, puede aparecer como una opción "legítima” de vida.

Por encima de todo, hay que destacar que, quienes los invitan a formar parte de estos grupos, claramente utilizan en su beneficio y aprovechan la inmadurez de estos adolescentes. Es decir, si bien los adolescentes

que se unen saben muy bien que están cometiendo actos ilegales, de ninguna manera cuentan con la capacidad y con la madurez para comprender plenamente el significado y la trascendencia que cometerlos tendrá para el resto de sus vidas. Muchos adolescentes, como veremos, dicen frases como: "se me hizo fácil...", "no pensé en las consecuencias...", “quería saber lo que se siente...", "quería tener lo que ellos tienen...", "me llamaban la atención las armas, los vehículos...”, etc.

Como lo señala un estudio reciente: el perfil del sicario, en su mayoría, es de personas que se desenvuelven en grupos sociales como individuos normales, con capacidad de amar y expresar afecto por sus seres queridos, al mismo tiempo que pueden ser despiadados con sus víctimas. Lejos del estereotipo del psicópata o del terrorista, el sicario realiza "un trabajo" en específico a cambio de una retribución; su lealtad es para con el contratante, lo que lo hace casi invisible ante la sociedad. En suma, el sicario es capaz de llevar una vida normal, paralela al papel que desempeña en el sub mundo criminal en el que se desenvuelve (Arias y Pacheco citados por Barragán 2015: 18).

Escucharemos ahora cinco

historias breves de adolescentes que dan cuenta con claridad de

cómo y por qué ingresaron a

grupos de la delincuencia organizada. Algunos también

proporcionan relatos muy detallados de los diferentes rangos que existían en los grupos que participaron, así como de la manera en que era posible ir escalando hacia niveles más altos en la jerarquía de dichos grupos. 
Hilario es un joven de 20 años que lleva tres años interno en Veracruz y todavía le faltan 7 años y medio para concluir su sentencia. Él dice que, cuando tenía 16 años se salió de su casa para ir a trabajar y que vivió solo durante un año y después regresó a vivir con su madre y sus hermanos. Héctor se salió de la escuela cuando inició la secundaría pues no le interesaba ya que prefería irse con sus amigos. Sus padres se separaron cuando él tenía 7 años. Su padre trabajaba en el campo, mientras que su madre trabajaba haciendo limpieza en casas y sólo cursó algunos años de la escuela primaria. Él comenzó a trabajar desde antes de los 12 años ayudando a una hermana que tenía un puesto en el mercado. Después trabajó como mesero en un restaurante, en un auto lavado y en una rosticería. El dinero que ganaba era en parte para sostenerse y otra parte para su madre. Él es el quinto de seis hermanos.

Aunque fue acusado de haber matado a una chica en un hotel "por problemas personales", relata que pertenecía a un grupo delictivo: "Yo me junté con un grupo un tiempo cuando viví solo. Me pedían que les guardara la droga. En ese grupo puedes estar hasta arriba o hasta abajo. Cuando estás hasta abajo te puedes salir, como yo, que era guerrero. Los guerreros se encargan de cuidar al tiendero, que son los que venden la droga. El guerrero se encarga de 'entuzar' (esconder) al tiendero. El guerrero es el nivel más bajo, luego sigue el tiendero y luego el halcón. Después del halcón siguen las estacas y luego el RT. Los RT's andan en los coches con los aparatos para avisarles a los tienderos; el RT es el encargado de llevar los radios, las armas, y andan en dos coches, pero depende de cada zona. En donde yo andaba, sólo había que cuidarse de policías, militares y marinos, pero no había contras, aunque a veces había chapulines, que son los que venden por su cuenta, pero a esos los matan rápido porque al grupo no le gusta que vendan sin pagar cuota, sin pago de piso. Es más difícil defenderse cuando hay contras que cuando sólo hay autoridades. Los policías municipales estaban todos comprados, no nos hacían nada, nos dejaban trabajar, pero a otros niveles era más difícil que estuvieran comprados".

Al preguntarle que cómo fue que ingresó por primera vez al grupo, dijo: "en mi caso, fue cuando me salí de vivir con mi hermana y me puse a trabajar por mi cuenta, y ahí llegaban halcones, tienderos, y te ofrecían el dinero y la droga y entonces caes...".

Señala que hay algunos compañeros que se deprimen por estar encerrados pero que él piensa que la mayoría de los jóvenes internos sale de la institución mejor que como entraron. Su mayor sueño sería poder ingresar al Ejército para servir, dice.

Vicente es un joven de 23 años que se encuentra, desde hace casi 6 años, recluido en el centro de internamiento de Ciudad Juárez y a quien todavía le faltan más de 9 años para terminar de cumplir con su sentencia. Él refiere que, desde los 15 años, se salió de su casa por problemas que tenía con su familia y con la escuela y que se fue a vivir con amigos y ya no regresó a su casa en donde viven sus padres y dos hermanos. Él terminó la escuela secundaria, pero dice que no le gustaba la escuela porque se aburría y no le gustaba 
levantarse temprano. Además, en la escuela lo corrieron por consumir drogas así que ya no pudo regresar. Su padre estudió la carrera de Ingeniero Electromecánico y su madre completó la preparatoria y se dedica al comercio. Al preguntarle si él trabajaba, dijo que se dedicaba a la venta de droga y que era sicario. Vicente no reporta malos tratos o humillaciones y señala que, cuando era pequeño, sus padres le ayudaban con las tareas, lo llevaban al médico, le preparaban los alimentos y lo llevaban de paseo. También señala que considera a sus padres como las personas que más lo han apoyado en su vida y que su madre es la persona en quien más confía.

Refiere que su abuelo y unos tíos estuvieron un tiempo en la prisión y no reporta que en su casa alguien consumiera alcohol o drogas, aunque, por su parte, él consumía mariguana, cocaína y pastillas diariamente antes de ingresar al centro de internamiento.

Vicente está acusado de homicidio, portación de arma prohibida y delincuencia organizada y relata lo siguiente: "al principio, me involucré en la delincuencia por unas amistades, pero, lo que me permitió continuar, fue porque no quise regresar a mi casa por orgullo, por los conflictos que teníamos a causa de que yo consumía drogas y no me gustaba que me dijeran nada. Entonces, uno necesita dinero y, cuando estás rodeado de esas amistades, te parece fácil, o en ese momento así lo piensas porque te orillan a hacerlo y en ese momento no te das cuenta, no piensas. Primero empecé por vender drogas y luego los homicidios. Siempre va a haber personas que se van a dejar influenciar por esos grupos; uno se deja influenciar por el dinero y por problemas familiares, pero también porque no nos orientan. Creo que se les debería mostrar a los chavos que sí pueden obtener dinero y lujos en el crimen, pero pueden perder a su familia o morir. Hay que mostrarles con testimonios y darle continuidad en las escuelas secundarias, en las preparatorias, no hay de otra". También influye mucho, dice, "sentirte parte de un grupo. Al principio piensas que son como tu familia, pero luego te das cuenta que no y entonces ya no te puedes salir a menos que te vayas a vivir a otro estado".

Al preguntarle a Vicente si ya lo habían detenido en ocasiones anteriores, contestó: "me habían detenido como unas seis veces, a veces por drog a y a veces por portación de arma o por homicidio, pero siempre me dejaban salir porque los policías estaban involucrados en el mismo grupo al que pertenecía la mayoría”.

Vicente opina que el trato que reciben en el centro de internamiento es "regular", tanto por parte del personal como de sus compañeros que, en ocasiones, lo han golpeado. También señala que "hay muchos internos y pocas actividades; yo ya tomé todos los cursos que ofrecen y no nos dan cursos nuevos o talleres para aprender oficios". Y, sobre si salen mejor o peor del centro de internamiento, dice: "he visto muchos que salen a lo mismo, vuelven a entrar o los asesinan, pero, si estás aquí durante un tiempo, empiezas a organizar tu mente y aprendes a madurar, sólo que, si no le importas a tu familia, ahí está el error porque la familia es la única que te puede ayudar. Yo quiero que mi familia se sienta orgullosa de mi'”.

Oscar es un chico de 17 años que lleva seis meses interno en Veracruz, y le queda por cumplir una sentencia de seis años. Sus padres se separaron cuando él tenía 7 años, 
edad a la que dejó de vivir con su padre mientras que continuó viviendo con su madre y sus hermanos hasta que lo detuvieron. Él inició el primer año de secundaria, pero no continuó en la escuela pues lo corrieron por llevar una navaja, además de que no le gustaba ir la escuela. Él no sabe hasta qué grado escolar cursaron su padre y su madre y dice que su padre se encuentra pensionado mientras que su madre es ama de casa. Oscar comenzó a trabajar desde los 15 años, primero, en un auto lavado y después como ayudante de albañil. Lo que él ganaba era en parte para sus gastos yen parte para su familia ya que tiene 6 hermanos y 15 medios hermanos. Refiere que, cuando era pequeño, contaba con el apoyo de su familia para las tareas escolares, que lo llevaban al médico cuando enfermaba y que siempre había alguien que le preparara la comida. Sin embargo, dice que no lo llevaban de paseo pues su situación económica no era muy buena, aunque no les faltaba comida.

Al preguntarle si había pertenecido a algún grupo delictivo, narró: "antes de que yo trabajara, me metí con un grupo, el Cartel del Golfo; ellos me dijeron que si quería trabajar con ellos y les dije que sí. Me daban 5 mil pesos a la quincena y trabajaba como halcón. Lo que yo hacía era hablar por teléfono y avisar si pasaba la policía o los militares. Así duré como un año y luego me dijeron que si quería ser 'estaca' pero yo no me sentía entrenado porque ellos traen armas, camionetas, era muy arriesgado. También están los que les llaman centrales que son los que les reportan a los halcones. Los 'estacas' y los centrales reportan a los jefes. Yo no sé cuántos formaban parte del grupo, pero éramos como 20 halcones en cada grupo, 30 estacas y dos centrales, uno de día y otro de noche y luego estaban los jefes, que eran dos, y ellos son los que decidian".

Oscar fue acusado por homicidio y secuestro, pero dice que detuvieron a las personas que iban pasando por ahí, porque en ese caso él no participó. Señala que no le informaron del delito que lo acusaban, ni de sus derechos, ni lo presentaron de inmediato ante las autoridades y tampoco les permitieron tener un abogado mientras estaban en SIEDO. Considera que el trato que reciben en la institución es bueno $\mathrm{Su}$ familia lo visita sólo tres veces al año porque vive lejos y no tiene suficientes recursos. Lo que más le gusta de la institución es que le da la oportunidad para continuar estudiando y que tiene tiempo suficiente para pensar. Lo que más le gustaría hacer cuando salga es ingresar a la Marina o bien ser Policía Ministerial. Su mayor sueño sería tener una familia y vivir en paz.

Pavel tiene 17 años, lleva casi dos años internado en Guadalajara y le quedan poco más de 4 años para cumplir con la sentencia. A los 12 años se enroló en el crimen organizado y decidió abandonar su casa cuando empezaron a buscarlo para "darle piso" (asesinarlo). Asistió a la escuela hasta los primeros grados de primaria, pero el ambiente familiar no le favoreció y se aburría porque no entendía a la maestra. No conoció a su padre y siente que le hizo falta; su madre, con primaria incompleta, trabaja desde hace muchos años en una gasolinera. Cuando se salió de la escuela, su mamá decidió mandarlo un año con su abuela para que lo cuidara, pero Pavel prefirió 
regresar a su casa y vagar por las calles de la colonia; dice que ahí conoció "lo bueno y lo malo" pues comenzó a realizar actividades para vendedores de droga del barrio que lo conectaron con policías en activo que trabajan para el crimen organizado. Lo entrenaron poco a poco para actuar como sicario, actividad que él refiere como su "trabajo".

Él es el segundo de cinco hermanos, uno de los cuales es su medio hermano. Dice que, cuando era pequeño, su madre era la única que trabajaba, por lo que la situación económica era mala y no tenían lo suficiente para vivir bien. Siempre sintió el apoyo de su madre, aunque tenía poco tiempo. Refiere que su madre es la persona que considera más valiosa y quien más lo ha apoyado en su vida, así como la persona en quien más confía. En el caso de su padre, considera que es la persona que más daño le hizo al no ocuparse de él. Dice que ningún familiar consumía alcohol o drogas cuando él era pequeño, aunque él, por su parte, comenzó a consumir alcohol y diversas drogas desde los 11 años y lo hacía diariamente antes de ingresar al centro.

Pavel fue acusado primero de secuestro, después se le relacionó con la ejecución de 26 personas, de las cuales comenta, él ejecutó a 10, aunque asegura que hizo otros "trabajos" (ejecuciones y secuestros) antes de ese caso.

Relata: "Cuando me sali de la escuela unos vecinos me daban para beber y marihuana, después me contactaron con policías y ellos me llevaron con el grupo. A los 11 años me integré al Cartel del Milenio y a los 12 me llevaron a vivir con ellos. El grupo lo integraban de 6 a 8 personas casi todas mayores de edad, y vivíamos en la misma casa. Mi trabajo consistía en levantar, secuestrar y ejecutar. Ellos elegían a las personas y yo cumplía con lo que me dijeran que había que hacer. Realicé muchas ejecuciones y 'levantones'y participé en algunos secuestros. Cada mes me pagaban mínimo 15 mil pesos y después de cada trabajo me daban alguna cantidad, una vez fueron 50 mil pesos. Una parte se la daba a mi mamá y la otra era para comprardroga.".

También dijo: "yo tenía mando porque era sicario. Otro compañero y yo éramos y hacíamos lo mismo, por eso estábamos debajo del jefe del grupo y debajo de nosotros estaban los supervisores, que también vivían en la casa, y los vendedores que eran muchos. Cuando no había trabajo, tenía que salir a supervisar que los distribuidores hicieran el trabajo en el territorio y ver si los vendedores estaban en sus puntos. Me consideraban muy bien en todas las tareas".

Lo detuvo la Policía Ministerial, y dice: "desde que me trasladaron, comenzaron a pegarme, pero en la Delegación fue peor. Me quitaron la ropa y comenzaron a darme toques con electricidad, patadas en cualquier momento, bolsa en la cabeza y respirar con la bolsa en la cabeza el agua con gas y el chile piquín. También intentaron cortarme los dedos de las manos y me metían una punta debajo de la oreja que me provocaba dolor hasta perder el conocimiento, me tiraban agua para despertar y me seguían golpeando. Las sesiones se repitieron por 10 días. Después estuve un mes en el hospital en tratamiento de recuperación".

Relata que, cuando lo detuvieron, lo apoyó su madre. Dice que lo que más le gusta de la institución es la oportunidad de poder seguir estudiando. Lo que más extraña es a su familia y caminar en libertad. Dice que estar en esa institución los ayuda y que dependerá de cada compañero salir mejor que como entraron. Cuando salga, se irá del estado por seguridad y le gustaría comenzar a trabajar y completar los estudien que le falten. También le gustaría formar una familia en el futuro y vivir bien. 
José Elías de 18 años, lleva casi dos años interno en Durango y le quedan casi dos años para cumplir con la medida de internamiento. Relata que su familia se encuentra vinculada al crimen organizado y desde muy pequeño presenció actividades ilícitas, particularmente la distribución de drogas y el lavado de dinero; incluso dice que acompañaba a su padre a ciertas actividades. Su participación inicial se debe a una venganza con unas personas que intentaron asesinar a su padre por lo que él, junto con sus hermanos, los localizaron y les dieron muerte, comenzando sus actividades dentro del cartel. Asistió a la escuela, pero no completó la primaria porque en su casa no la consideraban importante y se aburría en las clases. Su padre trabaja como músico para bandas de las que amenizan fiestas, sin embargo, señala que es solamente para dar la apariencia, porque sus mayores ingresos provienen de actividades ilícitas. Su madre, con primaria incompleta, se dedica lavar dinero y entregar cuentas. Desde pequeño sus padres lo han incentivado a tener una vinculación con el crimen organizado y, como él menciona, "a tener dinero fácil sin responsabilidades". A los 14 años, después de ejecutar a varias personas que atacaron a su padre, el jefe de la plaza lo llamó para que fuera su escolta. A los 16, conoció a su actual pareja con la que vive en casa de sus padres. Tienen una niña de tres años.

Él es el hijo el menor de sus 3 hermanos y relata que vivió en un ambiente familiar de descuido por las actividades de sus padres. Cuenta que, cuando era pequeño, la situación económica era buena, tenía todo y nunca faltó algo en su casa. Lo que faltó, dice, fue “tiempo para convivir familiarmente". Refiere que sus padres, son quienes más lo han apoyado en su vida, así como las personas en quienes más confía. Considera que nadie le ha hecho daño en su vida salvo élmismo. No refiere haber sufrido malos tratos, abusos o violencia cuando era pequeño.

Dice que sus hermanos han estado antes en prisión, que consumen drogas y alcohol, así como sus padres, por lo que él vivió en ese ambiente desde pequeño. También José Elías consumió alcohol y drogas de forma frecuente desde los 15 años. Fue acusado de homicidio calificado y robo agravado, aunque él solamente menciona éste último como motivo de su internamiento, aunque dice que decidió culparse como responsable del grupo para no tener problemas con el 'Patrón', como él se refiere al jefe de plaza.

Comenta que era reprendido constantemente por sus actitudes: "Por andar con el Patrón, se me subió, comencé a andar exhibiéndome y se lo reportaban. Por ejemplo, cuando yo andaba en la calle y me detenían, daba una clave y me dejaban pasar, tampoco me revisaban; pero comencé a

abusar de eso y andaba todo el tiempo mostrando la clave y, aunque me decían que los perjudicaba esa actitud, yo lo hacía porque me sentía poderoso...".

Luego, explica: “...yo era sicario, era parte de la guardia del jefe de la plaza. Tenía a mi cargo a otros 3. Mi tarea era supervisar la plaza, levantar a las personas, ejecutar y cumplir las órdenes". Por ejemplo, el jefe le pedía "buscar personas para los ministeriales y entregarlos. Era como un ministerial... tenía una clave para comunicarme con ellos...". 
Sobre el delito por el que fue detenido, José Elías cuenta: “...me acusan de robo agravado, pero no es cierto. Yo trabajaba para un cartel, pero, como no hacía caso, me pusieron de castigo mandarme para acá. Yo acepté porque mordí la mano del 'Patrón' y ni modo. Ni siquiera entendí de lo que me acusaban".

"Fui a buscar a un violador que andaba acosando en el barrio donde vivía, estuve buscándolo hasta que dimos con él y entramos a su casa. Le avisé al Patrón y me dijo que le diéramos una calentadita y luego lo entregáramos a los ministeriales, pero a los chavos se les pasó la mano y lo matamos. Le avisé al Patrón y se enojó, me mandó traer y me entregaron a los ministeriales, me dijo que andaba muy alzado y que me iban a dar un castigo, pero yo me culpé de todo porque era el responsable".

Relata que, cuando lo detuvieron, lo apoyaron sus padres. Refiere que el trato que reciben en la institución por parte tanto del personal como custodios es bueno y que ahí se porta bien porque quiere salir pronto. Lo que más extraña es a su familia, especialmente a su pareja y niño, "todos creen que nosotros no tenemos sentimientos, pero yo extraño a mi familia, no vienen mis padres porque tienen temor que pueda pasar algo, pero nos hablamos...".

Cree que no tiene otro destino que seguir en lo mismo porque su familia se encuentra en la misma actividad y por la ayuda que recibe de su jefe de plaza. Dice: “... voy a seguir en lo mismo, ahora me apoya otro patrón, porque al otro lo mataron. Me manda dinero, también le dan a mi esposa. Estoy comprometido cuando salga. Tengo que responder, pagar la ayuda que me dan.” Para terminar, agrega: “... no tengo sueños, creo que no puedo cambiar mi vida, me gusta el dinero fácil. Me criaron mis papás así, siempre con dinero".

\section{Pandillas}

El $27 \%$ de los adolescentes que entrevistamos, (122 de 452 casos), dijeron haber cometido algún delito en asociación con integrantes de la pandilla de la que formaban parte en el barrio o la colonia donde vivían. De acuerdo con su descripción, las características de estas pandillas eran muy similares a pesar de que las encontramos en todas las entidades que estudiamos. Aunque el número de los integrantes es muy variable, en la mayoría de los casos, estas pandillas se reunían para hacer deportes, ir a fiestas, beber alcohol o consumir drogas y defender su territorio frente a otros grupos similares con los que frecuentemente tienen riñas y disputas. En ocasiones, estas pandillas también se organizan para robar, principalmente con el propósito de obtener recursos para alcohol y/o drogas. Aunque no siempre el propósito de las pandillas es cometer delitos, en ocasiones éstos resultan de manera imprevista como resultado de las frecuentes riñas en que participan, y más aún cuando media el consumo de alcohol y/o drogas. A diferencia de lo que ocurre en los grupos de delincuencia organizada donde invariablemente los hechos de violencia involucran el uso de armas de fuego y de 
armas de alto poder, en las pandillas, cuando surge la violencia, casi siempre utilizan armas blancas, piedras, palos o botellas, aunque algunos adolescentes también refirieron el uso de armas de fuego.

Las pandillas son un fenómeno que ha sido bien estudiado en Latinoamérica (Perea 2007; Rodríguez 2013; Arraigada 2015). Uno de los factores que más se ha señalado, es la necesidad que tienen los adolescentes de pertenecer y asociarse, sobre todo, cuando han desertado de la escuela y tienen pocas expectativas de poder ingresar al mercado de trabajo formal. Los grupos de pares que se reúnen en las esquinas de los barrios populares, brindan a estos jóvenes la oportunidad de pertenecer a un grupo y tener una identidad generalmente asociada a un nombre.

Se ha dicho, también, que las pandillas representan el esfuerzo espontáneo de niños/as y jóvenes por crear, donde no lo hay, un espacio en la sociedad, en el cual puedan ejercer los derechos que la familia, el Estado y la comunidad les han vulnerado. Sus espacios de encuentro son las calles, las cuales ocupan con un sentido de pertenencia e identidad territoriales. Asimismo, producen códigos de identidad que se expresan en la creación de sus propias normas, ritos,

Ernesto es un chico de origen maya que se encuentra interno en Yucatán. Él tiene 15 años y lleva seis meses en el centro de internamiento y le queda un año para cumplir con su criterios de ingreso, conducta y disciplina, y simbologías que los diferencian de otros grupos y del resto de la sociedad. Otro aspecto fundamental es que la pandilla brinda a sus integrantes una,„comunidad emotiva $^{e e}$, una familia sustituta que satisface las necesidades afectivas del joven y le provee dignidad, además de un sentido y forma de vida (OEA 2007 y PNUD 2009, citados por Arraigada 2015:2).

Otro de los elementos que se ha mencionado es que los jóvenes, como cualquier otro ser humano, tienen necesidad de reconocimiento $\mathrm{y}$, cuando no están a su alcance los medios para adquirirlo de manera legítima, en ocasiones se valen de medios ilegítimos para ser reconocidos, para sentir que se les toma en cuenta, que son 'alguien' y que tienen un lugar en la sociedad.

Veremos a continuación la historia de un adolescente indígena que formaba parte de una pandilla en su colonia $y$, posteriormente, los relatos breves de otros adolescentes que también refieren haber cometido algún delito en pandilla. 
sentencia. Él estudió apenas la mitad de la primaria, y aunque le gustaba mucho ir a la escuela, tuvo que salirse porque su padre lo obligaba a trabajar. Su padre también cursó solo los primeros años de la primaria y se dedica a la albañilería y su madre tampoco terminó la primaria y es ama de casa. Ernesto, por su parte, desde los 7 años ha trabajado también en la albañilería, así como en una panadería y una vulcanizadora, aunque no le pagaban pues ayudaba a su padre. Cuando él tenía 10 años, sus padres se separaron y Ernesto cuenta: "hasta los 10 años viví con mi papá, pero me obligaba a trabajar y de los 10 a los 15 viví con mi mamá, mi padrastro y dos hermanos". También relata que, cuando era pequeño, nadie le ayudaba a hacer sus tareas, no lo llevabanal doctor cuando se enfermaba y tampoco jugaban con él ni le compraban ropa, lo llevaban de paseo o le celebraban sus cumpleaños

Él considera que su madre es la persona que más lo ha apoyado mientras que su padre es la que menos lo ha apoyado. Refiere que la persona en la que más confía son sus amigos y señala que su padre lo golpeaba, lo maltrataba y lo insultaba cuando era pequeño y que no encontraba nadie que lo apoyara cuando eso ocurría. También refiere que su padre bebía alcohol y consumía drogas con frecuencia y que tanto su padre como unos tíos han estado en prisión. Ernesto, por su parte, refiere que él consumía alcohol y también consumía mariguana, crack, piedra, solventes y unas pastillas a las que llama Pokemón y que varias de estas sustancias las consumía diariamente. Él explica: "las Pokemón son para no dormir, para estar más thriller, y el Clonazepam es para dormir, para olvidar las cosas. Después de que pasa el efecto, queda la jaqueca. Desde los 10 años, me ponía a trabajar o a robar para la drog a y también me compraba pura ropa cholera; yo solito me compraba mi ropa. Ahora me la compra mi mamá porque ya salió adelante, mi padrastro la ayuda, ya con ella no tengo maltratos".

Ernesto fue acusado por robo con violencia. Él relata que formaba parte de una pandilla: “jugábamos, íbamos a fiestas, nos drogábamos y peleábamos con otra banda ... yo robé y asalté a un morro en la esquina de mi casa porque estaba con efectos de la droga y le pegué y le quité su dinero y sus cadenas". También relata que, con anterioridad, ya lo habían detenido como ocho veces "por 'mariguano', por vandalismo y por echar 'refuegos' y 'pedrones' contra otra banda”. Y, al preguntarle si la policía lo había golpeado, contestó: "te echan gas lacrimógeno, te dan toques feos, te pegan de patadas, te dan tehuacanazos y te roban tu dinero y tu celular". También señaló que las autoridades que lo detuvieron no le dijeron de qué delito lo acusaban, ni le informaron que tenía derechos, ni lo presentaron de inmediato al Ministerio Público ni le dijeron que tenía derecho a contar con un abogado. Cuando ya pudo contar con un abogado, dice que no lo defendió ni hizo nada por él.

Dice que su madre y su padrastro lo han apoyado y lo visitan en el centro de internamiento. Al preguntarle qué es lo que más extraña, contestó: "los cigarros, las fiestas y las chavas". Dice que en el centro se siente solo, aburrido y desesperado y que, cuando salga, lo que más le gustaría hacer es ir a ver a su novia. Le gustaría estudiar la carrera de Química, aunque considera poco probable que pueda hacerlo. Y, al preguntarle si considera que los chicos salen mejor, peor o igual de la institución, dice: "salen igual porque, lo que no hacías, si te encierran, lo vas a hacer doble, así me pasó cuando me llevaron al anexo para que no me drogaran; sali y me drogué mucho más". 


\section{Delitos individuales}

En 170 de las entrevistas realizadas a los y las adolescentes (38\% del total), encontramos que cometieron delitos violentos de manera individual o acompañados de alguien más, pero siempre motivados por conflictos interpersonales en contra de familiares o rivales. También estos delitos (homicidio, lesiones) pudieron haber surgido como resultado involuntario en la comisión de otro delito (robo) que se cometió de manera individual. Lo que distingue, en todo caso, a esta modalidad de delitos de las dos anteriores, es que los y las adolescentes no formaban parte, ni de un grupo organizado para cometer delitos de manera sistemática, ni de una banda o pandilla, sino que actuaron de manera y por motivos o conflictos de carácter individual o interpersonal. El caso de Yolanda ilustra con claridad las características de estos delitos.

Yolanda es una joven que lleva tres años interna en un centro para adolescentes en el Estado de Chihuahua y quien tiene una pena de 14 años por haber dado muerte a sus padres adoptivos. Ella estudió hasta el primer grado de la preparatoria antes de ingresar y dice que le gustaba mucho estudiar. Su padre biológico es un hombre que pide limosna en las calles de la ciudad. Su madre biológica murió de SIDA cuando ella nació. Cuando ella tenía un año, fue adoptada por una pareja en la que el padre tenía 65 años y la madre 45. Este era el segundo matrimonio para el señor que tenía seis hijos de una unión previa. Ella explica: "los hijos de mi papá adoptivo no eran como mis hermanos, no procuraban a su papá más que para pedirle dinero y eso me molestaba mucho. Ellos ya eran mayores de edad cuando yo era pequeña".

Ella habla de su padre adoptivo como su "padrastro" y refiere haber sufrido malos tratos, humillaciones y abusos sexuales por parte de él cuando era pequeña. Señala también que su madre adoptiva le tenía miedo a su padrastro y por eso no la defendía. El padrastro consumía alcohol con frecuencia y era dueño de varios bares y cantinas en la localidad, así como tenía diversas propiedades y cuentas bancarias, por lo que tenía una buena posición económica. "Yo quería amor

- dice Yolanda- y ellos sólo lo compraban todo con dinero, pero nunca mostraban su cariño con humildad. Nadie va a entender lo que yo aguanté muchos años; no lo hice porque sí, tuve mis motivos. Yo, desde los diez años, tenía mucho coraje contra los dos por golpes, regaños, presiones, humillaciones y la edad de ellos no ayudaba, teníamos muy mala relación. Yo sólo tenía confianza con mi pareja y un día le dije que si me ayudaba a matarlos y me dijo que sí y él le dijo a un amigo suyo que también nos ayudó. Mi novio y su amigo tenían 18 años y ahora se encuentran en la cárcel con una sentencia de 37 años. Yo lo planeé, les dije a qué hora fueran a mi casa, les dije que quería que mis papás tuvieran una muerte rápida y no sangrienta así que el amigo estranguló a mi 
mamá y mi novio asfixió a mi papá... Yo fingí que los habían secuestrado y comenzaron a investigar a todos mis tíos y no pensé que me iban a entrevistar a mí y también entrevistaron a mi novio y como caímos en contradicciones, se dieron cuenta y yo prácticamente me entregué. Yo estaba en shock, no asimilaba nada y no podía creer lo que había sucedido, yo no lloraba, contestaba todo tranquila, sin alterarme... la jueza me dijo cosas muy feas, dijo que yo no era normal ni sociable, que era psicópata porque nunca me vio llorar. Lo que pasa es que yo estaba en shock, no asimilaba nada y no podía creer lo que había sucedido...".

Estando interna ha recuperado la relación con su papá biológico quien la visita cada semana y la apoya. Dice que estar interna le ha servido "para aprender nuevas cosas y para valerme por mí misma y aprender a valorar las cosas. Ahora he podido extrañar a mis papás adoptivos y llorar por ellos, concluye”. Cuando recobre su libertad, a Yolanda lo que más le gustaría es poder llegar a ser una bailarina profesional.

En contraste con las dos modalidades anteriores, la de los delitos que son motivados por conflictos de carácter individual o interpersonal, son, quizás, los que, desde el punto de vista de las políticas públicas, sea más difícil poder prevenir o evitar. Sin embargo, asegurar que existan políticas de calidad que promuevan la mediación y la solución pacífica de conflictos, así como la atención y acompañamiento de los casos de abuso y violencia intrafamiliar, tal vez podrían contribuir a evitar o reducir la incidencia de esta clase de delitos.

\section{Conclusiones}

El estudio más amplio que realizamos da cuenta con detalle de las situaciones de vulnerabilidad que los y las adolescentes han enfrentado $\mathrm{y}$ que precedieron, y en buena parte contribuyeron, a su involucramiento en actividades delictivas. Estas son, por así decir, las condiciones de vulnerabilidad primaria que enfrentaron en su entorno.

De igual modo, el estudio más amplio muestra con detalle que, a las condiciones de vulnerabilidad primaria, se agregan las que tienen lugar cuando los y las adolescentes entran en contacto con las instituciones de seguridad y justicia. Denominamos a éstas como condiciones de vulnerabilidad secundaria. Con ello nos referimos a las dificultades que muestran estos sistemas para operar, en todas sus fases, dentro del marco de la ley y proporcionar, así, a los adolescentes una experiencia de legalidad y de ejercicio de derechos. 
El estudio, -del cual hemos mostrado aquí sólo una parte-, nos permitió concluir que, la mayoría de los adolescentes que escuchamos, atravesaron por experiencias difíciles y dolorosas que les han producido daños importantes y que ellos, a su vez, han replicado en los demás. Desafortunadamente, los elementos que les brindan los centros de internamiento, no siempre les permiten hacerse cargo de su responsabilidad, comprender a fondo su situación y estar en condiciones de reparar los daños físicos $\mathrm{y}$ emocionales que han sufrido y que han hecho padecer a otros.

Como diversos estudios internacionales han mostrado (Department of Justice 2012; MacArthur 2015), es importante poder ayudar a los adolescentes en el sistema de justicia a sanar, respondiendo de manera apropiada a sus necesidades de desarrollo y asegurando que el sistema en sí mismo no les produzca más daños. Cuando los adolescentes traumatizados violan las leyes y se involucran en actividades delictivas, incluso de manera repetida, ellos aun necesitan y merecen la ayuda por parte de los adultos. Los sistemas deben tener la capacidad para reconocer la pesada carga que algunos niños y adolescentes llevan, y ayudarlos a transitar hacia una adultez saludable y productiva, proveyéndoles servicios que tomen en cuenta los daños que les ha provocado el haber estado expuestos a la violencia. Con mucha frecuencia los sistemas de justicia se apoyan en respuestas punitivas y hacen juicios que resultan tan dañinos como inefectivos para los adolescentes infractores.

Queda claro, entonces, que nuestro país tiene mucho por hacer para brindar mejores condiciones a sus niños, niñas y adolescentes, especialmente a aquellos que se encuentran en circunstancias de mayor vulnerabilidad. Y hay también mucho por hacer para que los sistemas de justicia logren proporcionar a los y las adolescentes los elementos, las herramientas que requieren para poder efectuar el tránsito hacia la edad adulta en las mejores condiciones posibles que les permitan reducir su situación de desventaja en relación con otros jóvenes del país. De no hacerlo, se les estará condenando a vivir de manera permanente en condiciones de desventaja, sin que 
logren desarrollar todo su potencial y sus capacidades y sin que tengan la oportunidad de aportarlos en beneficio de ellos mismos y de la sociedad.

\section{Bibliografía}

ARRIAGADA, M.I. (2015) Identidad violenta en los jóvenes: análisis de cómo influye la familia y cómo se refuerza en las maras y/o pandillas. Santiago de Chile, Chile: Diplomado en Prevención del Delito a Nivel Local.

AZAOLA, E. (2015) Diagnóstico sobre los adolescentes que cometen delitos graves en México.

Ciudad de México: UNICEF-Secretaría de Gobernación.

BARRAGÁN, A.J. (2015) "Por el recorrido de la vida y la muerte: identidad y aprendizaje social de jóvenes sicarios en Sonora", Tesis de Maestría en Ciencias Sociales, El Colegio de Sonora.

BONNIE, R., Johnson, R., CHEMERS, B. and SCHUCK, J. (2013) Reforming Juvenile Justice: A Developmental Approach. Washington DC: National Academies Press. http://nap.edu/catalog/14685/reformingjuvenile-justice-a-develpmental-aproach

CAUFFMAN, E., and Steimberg, L. (2000) (Im)maturity of judgment in adolescence: Why adolescents may be less culpable than adults. Behavioral Sciences and the Law 18:741-760.

Department of Justice (2012) Report of the Attorney General's National Task Force on Children Exposed to Violence. Washington DC: Department of Justice.
FARRINGTON, D.P. (1986) Age and Crime. Crime and Justice: A Review of Research 7:189-250.

Ley Nacional del Sistema Integral de Justicia para Adolescentes, Publicada en la Gaceta Parlamentaria de la Cámara de Diputados No. 4519-XX el 29 de abril de 2016.

MacArthur Foundation (2015) Juvenile Justice Report 2015. Chicago, IL:

MacArthur Foundation.

MONAHAN, K.C., et al (2009)

Trajectories of antisocial behavior and psychosocial maturity from adolescence to young adulthood. Developmental Psychology 45(6):1654-1668.

MULVEY, Edward (2011) Highlights from pathways to Desistance: A Longitudinal Study of Serious Adolescent Offenders. Washington DC: Department of Justice, Office of Juvenile Justice and Delinquency Prevention, March. https://www.ncjrs.gov/pdffiles_I/ojjdp/230 971.pdf

PEREA, C.M. (2007) Con el diablo adentro. Pandillas, tiempo paralelo y poder. Ciudad de México: Siglo XXI Editores.

ROBERSON, Clifford (2010) Juvenile Justice. Theory and Practice. Boca Raton, FL: CRC Press.

RODRÍGUEZ, Ernesto (2013) “Jóvenes, violencias y cultura de paz en América 
Central: enfoques, dilemas y respuestas a desplegar en el futuro". Foro de Ministros de Desarrollo Social de América Latina y el Caribe, UNESCO.

Save the Children (2016) Las y los adolescentes que México ha olvidado. https://www.savethechildren.mx/sites/savet hechildren.mx/files/resources/Las\%20y\%2 $010 \mathrm{\%} \% 20 \%$ 20adolescentes $\% 20$ que $\% 20$ Mexico $\% 20$ ha \%20olvidado_0.pdf

STEINBERG, L., Blatt-Eisengart, I., \& Cauffman, E. (2006) Patterns of Competence and Adjustment among Adolescents from Authoritative, Authoritarian, Indulgent, and Neglectful Homes: A Replication in a Sample of Serious Adolescent Offenders. Journal of Research on Adolescence, 16(1), 47-58.

STEINBERG, L., Chung, H. L., \& Little, M. (2004) Re-entry of Young Offenders from the Justice System: A Developmental Perspective. Youth Violence and Juvenile Justice, 1 (1), 21-38.

STEINBERG, L. \& Monahan, K.C. (2007) Age Differences in Resistance to Peer Influence,

Developmental Psychology, 43(6), 15311543.

STEIMBERG et al. (2015) Psychosocial Maturity and Desistance from Crime in a Sample of Serious Juvenile Offenders. Juvenile Justice Bulletin, March, Office of Juvenile Justice and Delinquency Prevention, U.S. Department of Justice. 